\title{
Use of two recipient lists for adults requiring heart transplantation
}

\author{
Hillel Laks, MD \\ Daniel Marelli, MD \\ Gregg C. Fonarow, MD \\ Michele A. Hamilton, MD \\ Abbas Ardehali, MD \\ Jaime D. Moriguchi, MD \\ Jessica Bresson, BS \\ David Gjertson PhD \\ Jon A. Kobashigawa, MD \\ For the UCLA Heart Transplant Group*
}

See related editorial on page 23

From the Heart Transplant Program, University of California, Los Angeles, Calif.

Presented in part at the annual meeting of the International Society of Heart and Lung Transplantation, Osaka, Japan, April 2000.

Received for publication Jan 24, 2002; revisions requested April 18, 2002; revisions received June 4, 2002; accepted for publication July 8, 2002.

*For other members of the Heart Transplant Program, University of California, Los Angeles, see end of article.

Address for reprints: Hillel Laks, MD, UCLA School of Medicine, 10833 Le Conte Ave, 62-182 CHS, Box 951741, Los Angeles, CA 90095-1741 (E-mail:Llaks@ mednet.ucla.edu).

J Thorac Cardiovasc Surg 2003;125:49-59

Copyright (C) 2003 by The American Association for Thoracic Surgery

0022-5223/2003\$30.00+0

doi: $10.1067 / \mathrm{mtc} .2003 .62$
Objective: An alternate (second) adult recipient list was used to match excluded potential recipients with nonstandard donor hearts that would otherwise be unused.

Methods: The only absolute criterion for entering the alternate recipient list was age: 65 years old before 1998 and 70 years old after that. Group I consisted of alternates who underwent transplantation, and group II consisted of 401 contemporaneous recipients. Hearts were first offered to regularly listed patients. At least one of the following donor risks accounted for allocation to an alternate: coronary artery disease, reused transplanted heart, high-risk behavior, hepatitis seropositivity, decreased left ventricular ejection fraction, high inotropic requirement, left ventricular hypertrophy, age older than 55 years plus another risk, and small donor with no other matches.

Results: Of 102 alternates, 82 were listed were because of age. After a median wait of 107 days, 62 alternates underwent transplantation. Median alternate recipient age was 67 years (vs 54 years, $P<.001$ ). Median donor age was 45 years (vs 31 years, $P<.001)$. Survival for alternates at 90 days was $82 \%$ (vs $91 \%, P=.04$ ). Significant recipient predictors of early mortality on multivariable analysis $(n=463)$ were previous cardiac surgery (odds ratio $2.74,95 \%$ confidence interval 1.37-5.48) and renal dysfunction (odds ratio 1.39, 1.10-176). Alternate listing did not independently predict early or late mortality. Late ( $>90$ days) death rates per 1000 person-months were 4.3 and 3.6 for groups I and II (relative risk 1.2, 0.62-2.36).

Conclusions: Use of two adult recipient lists facilitated allocation of unused donor organs. Satisfactory long-term survival supports the use of an alternate recipient list.

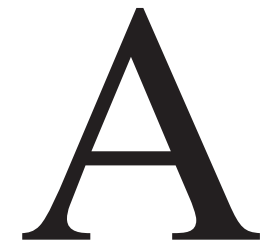

s wait times for heart transplant recipients increase, nonstandard donor hearts are being used for higher risk recipients and for status I (critically ill) patients, while older recipients are potentially not listed. ${ }^{1-6}$ In such cases the risk/benefit ratio justifies such a donor while expanding the pool of available hearts. Despite this, as many as $40 \%$ of organs remain unused, prompting our program to create an alternate recipient list in 1992. Borderline recipients who otherwise would be excluded from transplantation were considered for the alternate list and, 
once accepted, were educated as to the possible risk factors associated with the donor hearts that would be assigned to them.

\section{Patients and Methods \\ Patients}

This report includes all patients entered to December 1999. All those who have undergone transplantation have at least 1 year of follow-up. Age was the only absolute criterion for alternate recipient listing. Until 1998, age for placement on the alternate list was greater than 65 years. In 1998 this age was raised to 70 years. Since 1999, patients between 65 and 70 years have been offered the option of regular listing combined with alternate listing. Also included on the alternate list were patients with moderate renal insufficiency or peripheral vascular disease. Informed consent was obtained from all patients at the time of listing. The final consent to accept an organ was made after a discussion that included both the treating surgeon and the cardiologist. The use of two adult lists for heart transplantation was reviewed by our hospital ethics committee.

\section{Comparison Group}

Alternates who underwent transplantation (group I) were compared with 401 consecutive patients ( $\geq 12$ years old) who could have accepted the donor hearts by virtue of size (group II). This contemporaneous cohort underwent heart transplantation according to the criteria delineated in the 24th Bethesda Conference. ${ }^{7}$ Urgent priority (status I) was not offered to alternate recipients so that they would not be competing for organs with regularly listed patients. Outpatient assist device placement was, however, permitted.

\section{Donor Heart Allocation}

Donor hearts were considered nonstandard as outlined in Appendix Table $1 .{ }^{8}$ These were first offered by third-party organ procurement organizations to regularly listed patients according to United Network for Organ Sharing geographic allocation guidelines. Nonstandard hearts were used by us or others for regularly listed patients, usually waiting as status I. If the heart was refused by us (for example, if it was hepatitis $\mathrm{C}$ seropositive and the recipient was young or refused such a donor), then we instructed the organ procurement organization to call us back if the heart remained unused. We then considered the organ for alternate recipients. ${ }^{3}$

\section{Preservation}

Preservation solution consisted of University of Wisconsin solution. ${ }^{9}$ Reperfusion consisted of leukocyte-depleted, aspartate- and glutamate-enriched, warm blood cardioplegia (Buckberg solution) for 3 to 4 minutes, followed by leukocyte-depleted blood (8 minutes). Separate anastomoses of the superior and inferior venae cavae were used for the right atrium. ${ }^{10}$

\section{Immunosuppression and Prevention of Infection}

Methylprednisolone $(7 \mathrm{mg} / \mathrm{kg})$ was given on reperfusion, on separation from cardiopulmonary bypass, and at a dose of $125 \mathrm{mg}$ every 12 hours for three doses. Cyclosporine was administered with the aim of achieving a level of $250 \mathrm{ng} / \mathrm{mL}$. Azathioprine was administered at $2 \mathrm{mg} / \mathrm{kg}$ and at half dose for older recipients (unusually $>65$ years old) not exhibiting rejection. Prednisone was initiated at $1 \mathrm{mg} /(\mathrm{kg} \times \mathrm{d})$ and tapered to $0.1 \mathrm{mg} /(\mathrm{kg} \times \mathrm{d})$ during the course of 3 months. ${ }^{11}$ For those patients with few rejections, complete weaning from steroids was attempted. Since July 1994, all patients have received pravastatin after the operation. Older recipients ( $>65$ years old) showing absence of rejection were targeted for lower cyclosporine levels (by 10\%-20\%).

In case of cytomegalovirus positivity in either the donor or recipient, ganciclovir was administered intravenously for 2 weeks at a dose of 2.5 to $5.0 \mathrm{mg} /(\mathrm{kg} \times \mathrm{d})$, adjusted for renal function. This was followed by per os administration for 3 months at a dose of 1 to $3 \mathrm{~g} / \mathrm{d}$. This was extended for an additional 3 months if rejection (and treatment) or chronic illness occurred. Doublestrength trimethoprim-sulfamethoxazole tablets $(160-800 \mathrm{mg})$ were administered twice daily 2 days per week for 6 months. An additional 6-months course was repeated if patients had been treated for rejection during the 6 months before planned cessation. Clotrimazole $(10 \mathrm{mg})$ was administered as a lozenge three times daily for 3 months and extended in the case of treatment for rejection. Beyond 6 months after the operation, influenza vaccination was recommended for patients who exhibited a low risk of rejection.

\section{Statistical Methods}

Analysis was performed with Excel 97 (Microsoft Corp, Redmond, Wash), SPSS 8.0 (SPSS Inc, Chicago, Ill), and STATA (Stata Corporation, College Station, Tex). Averages were compared with the Student $t$ test, and proportions were compared with the Pearson $\chi^{2}$. Kaplan-Meier analysis with log rank test was used for survival and freedom from graft coronary artery disease (CAD). $P$ values were calculated with the Wilcoxon rank-sum test for continuous variables and the Fisher exact test for categoric variables.

Regression models were used to study covariates (Appendix Table 2A), including the designation of alternate recipient. Early and late mortality and graft CAD-free survival for all patients ( $\mathrm{n}=$ 463) were analyzed; 95\% confidence intervals (CIs) are shown when available. A separate analysis was used to study early mortality among alternate list patients only $(\mathrm{n}=62)$. Selection models were used on a backward-stepping algorithm with $P_{\text {remove }}$ of .15 and $P_{\text {enter }}$ of .10. The global test of proportional hazard assumptions (for Cox regression analysis of long-term outcome) was based on Schoenfeld residuals. Plots of natural log of survival for categories of the selected independent variables versus natural log of time did not show gross violations regarding proportionality assumptions.

\section{Results}

\section{Listed Patients}

One hundred two alternate recipients aged 34 to 74 years were listed (Table 1). Of those listed, 82 were on the alternate list for advanced age alone. More than half had ischemic cardiomyopathy, and $84 \%$ were male. Median maximum oxygen consumption was $12.4 \mathrm{~mL} /(\mathrm{kg} \times \mathrm{min})$. Sixty-two alternates underwent heart transplantation to De- 
TABLE 1. Reasons for listing as alternate recipient $(\mathbf{n}=$ 102)

\begin{tabular}{lr}
\hline Reason & No. \\
\hline Age alone & 82 \\
Retransplantation in combination & 7 \\
Renal insufficiency* & 2 \\
Age & 1 \\
Peripheral vascular disease & 1 \\
Obesity† & \\
Other risk factors & 4 \\
Obesity† & 2 \\
Peripheral vascular disease & 1 \\
Renal dysfunction & 1 \\
Jehovah's Witness & 1 \\
Chagas disease &
\end{tabular}

*Renal insufficiency according to criterion of serum creatinine level greater than $2.2 \mathrm{mg} / \mathrm{dL}$.

tObesity considered to be body mass index greater than $30 \mathrm{~kg} / \mathrm{m}^{2}$.

cember 1999. Four patients were removed from the list for malignancy, and 10 died while waiting. Two patients received an electric HeartMate (Thoratec Corporation (Pleasanton, Calif).) assist device; both were discharged. One has died, and 1 continues to wait. Neither was listed status I at any time.

\section{Donors}

From July 1992 to 1999, our institution accepted 182 nonstandard donor hearts. Of these, 120 went to regular list patients and 62 were allocated to alternates. The median donor age for transplanted alternates was 45 years, compared with 31 among regularly listed transplant recipients $(P<.001)$. Median donor/recipient height ratios were comparable for both groups (1.01 vs $1.01, P=.64$ ). Donors allocated to alternate recipients more often had atraumatic intracranial bleeding (aICB) as a cause of death $(50 \%$ vs $31 \%, P=.006)$. Of the 62 alternates, 25 came from local area, defined as a travel time of less than 60 minutes by any mode of transportation. Median graft ischemia time was significantly longer for alternates (197 minutes vs $181 \mathrm{~min}-$ utes, $P=.003$ ). The most common donor risks for alternates were high inotrope requirement, left ventricular hypertrophy (LVH), CAD, or hepatitis C seropositivity (Table 2).

\section{Recipients}

Recipients for the alternate and comparison groups are summarized in Table 3. Alternates were older and more frequently had undergone previous cardiac surgery. They also had decreased renal function relative to the others. Alternate recipients had shorter waiting times than did status II regular list patients (107 vs 158 days, $P=.04$ ). Four alternates were 65 years old, and 6 were less than 60 years old. Thirty-seven were aged 65 to 70 years old, and 15 were
TABLE 2. Risk factors for nonstandard donor hearts initially refused by our program and other institutions and subsequently allocated to alternate recipients $(n=62)$

\begin{tabular}{ll}
\hline Risk factor* & No. \\
\hline High inotropic requirement & \\
Isolated & 6 \\
High inotropic requirement plus substance abuse & 2 \\
High inotropic requirement plus recent cardiac arrest & 2 \\
LVH & \\
Isolated & 6 \\
LVH plus high inotropic requirement & 2 \\
LVH plus hepatitis C & 1 \\
CAD & 7 \\
Isolated & 1 \\
CAD plus high inotropic requirement & 5 \\
CAD plus LVH & 2 \\
CAD plus hepatitis C seropositivity & 7 \\
Hepatitis C seropositivity (isolated) & 5 \\
Chest trauma with myocardial contusion & 4 \\
Smaller donor, no other matches & 4 \\
Age $>$ 45 y, coronary angiogram not available & 3 \\
Extensive intravenous drug abuse with seronegativity for & \\
HIV & \\
Reused donor heart† & 2 \\
Older age, long ischemia (515 min) & 1 \\
Older age, hepatitis C-seropositive spouse & 1 \\
Hepatitis B, anti-hepatitis B core antigen (immunoglobulin & 1 \\
G) positive (immunoglobulin M unknown) & \\
\hline
\end{tabular}

*Definitions and abbreviations per Appendix Table 1.

tPerioperative massive cerebrovascular accident in recipient.

older than 70 years. The oldest recipient was 74 years old. During the study period, the number of alternate recipient transplants increased as much as 14 per year, shadowing an increase in the number of newly listed alternates (Figure 1). During the same period our program's volume increased from 60 to 70 patients/y to 90 to 1000 patients/y. In 1998, when age for inclusion on the alternate list was raised from 65 to 70 , the number of newly listed alternates decreased by $39 \%$, and we observed a parallel decrease in the number of transplantations among patients on the alternate list. In the comparison group, 229 of 401 recipients (57\%) were status I. Of these 229 patients, $51 \%$ received non-standard donor hearts. One percent of those in the comparison group who were status II received a nonstandard heart. This was due to previous knowledge of borderline stability and virtually class IV symptoms but not requiring intravenous inotropes. Twenty-four patients (of 401) in the comparison group were on a ventricular assist device; 3 patients among the 62 alternates were receiving continuous intravenous inotropic infusions.

\section{Survival}

Three alternates who received hearts with $\mathrm{LVH}, \mathrm{CAD}$, and long distance (heart coming from outside our local area) died from graft failure. Five others died of recipient risk 
TABLE 3. Transplanted recipient characteristics

\begin{tabular}{|c|c|c|c|}
\hline Characteristic & Alternates $(n=62)$ & Regular $(n=401)$ & $P$ value \\
\hline \multicolumn{4}{|l|}{ Patient demographic variables } \\
\hline Age (y, median and interquartile interval) & $67(3)$ & $54(17)$ & $<.001$ \\
\hline Gender ( $\%$ male) & $79 \%$ & $72 \%$ & .28 \\
\hline Previous cardiac surgery & $64 \%$ & $47 \%$ & .01 \\
\hline Retransplantation & $14 \%$ & $4 \%$ & .004 \\
\hline $\begin{array}{l}\text { Serum creatinine }(\mathrm{mg} / \mathrm{dL} \text {, median and } \\
\text { interquartile interval) }\end{array}$ & $1.5(0.8)$ & $1.3(0.7)$ & .01 \\
\hline \multicolumn{4}{|l|}{ Diagnosis } \\
\hline Ischemic cardiomyopathy & $60 \%$ & $45 \%$ & .04 \\
\hline Dilated cardiomyopathy & $21 \%$ & $33 \%$ & .08 \\
\hline Graft CAD & $14 \%$ & $3 \%$ & $<.001$ \\
\hline Congenital heart disease & 0 & $3 \%$ & .99 \\
\hline Valvular cardiomyopathy & $2 \%$ & $4 \%$ & .71 \\
\hline Viral cardiomyopathy & $2 \%$ & $3 \%$ & .99 \\
\hline Postpartum cardiomyopathy & 0 & $2 \%$ & .6 \\
\hline Other* & $2 \%$ & $8 \%$ & .11 \\
\hline \multicolumn{4}{|l|}{ Median wait (d, interquartile interval) } \\
\hline Status 1 at time of transplant & - & $29(112)$ & \\
\hline Status 2 & $107(211)$ & $158(294)$ & .04 \\
\hline Overall & $107(211)$ & $60(228)$ & .11 \\
\hline
\end{tabular}

$P$ values were calculated with Wilcoxon rank-sum test for continuous variables and Fisher exact test for categoric variables.

*Other diagnoses included hypertrophic cardiomyopathy $(\mathrm{n}=3$ ), alcoholic cardiomyopathy $(\mathrm{n}=2)$, doxorubicin-induced cardiomyopathy ( $\mathrm{n}=3$ ), acute rejection $(n=1)$, restrictive cardiomyopathy $(n=1)$, and Marfan syndrome $(n=1)$.

factors: 2 from stroke and 3 from multisystem organ failure. There were 11 in-hospital deaths, translating into a 90-day survival of $82 \%$. In contrast, the comparison group had survival of $91 \%(P=.04)$ at 90 days. Causes of death are listed in Appendix Table 3.

Median follow-up time for all 463 patients in this study was 3.25 years. As of June 2001, a total of 13 alternates had follow-up beyond 4 years; 12 are still alive. Death rates per 1000 person-mo were 9.0 for alternate recipients and 5.8 for the comparison group. Overall 4-year survival was $68 \%$ (vs $77 \%$, relative risk 1.55, 95\% CI 0.96-2.48, $P=.11$; Figure 2, left). Beyond 90 days, death rate per 1000 person-mo was 4.3 for alternates (vs 3.6, relative risk $1.2 ; 95 \%$ CI 0.62 $2.36, P=.77$; Figure 2, right).

\section{Graft Coronary Artery Disease and Rejection}

Eleven donor hearts required revascularization (average 1.8 vessels), 10 with bypass grafting and 1 with angioplasty. Patency of grafts at last follow-up was 63\%. As stated previously, there were 3 early deaths among these patients. Four other donor hearts also had evidence of CAD but did not require revascularization. Including these 15 recipients, 4-year freedom from any CAD was $67 \%$ (vs $78 \%$ for others, relative risk 1.94; $95 \%$ CI 1.10-3.43, $P=.04$ ). Excluding them, freedom from graft CAD was $76 \%$ for both groups. Freedom from grade III rejection at 1 year was $90 \%$ (vs $70 \%$ for regularly listed transplant recipients, $P=.001) .{ }^{11}$ Eight alternates had one episode each of at least grade III or presumed rejection. ${ }^{11}$ Freedom from rejection at 1 year was
$90 \%$ (vs $70 \%$ for regularly listed transplant recipients, $P=$ $.001)$.

\section{Multivariable Analyses}

Survival at Less Than 90 Days (Groups I and II Combined, $n=463$ ) Recipient previous cardiac surgery and poor renal function were risk factors for early mortality. Odds ratios were 2.74 (95\% CI 1.37-5.48) and 1.39 (95\% CI 1.10-1.76). Donor death from aICB was also found to be a risk factor (odds ratio 2.84, 95\% CI 1.51-5.34). Goodnessof-fit $\chi^{2}$ in the selection model had a $P$ value of .54. Odds ratio for alternate listing was 1.36 (95\% CI 0.53-3.5; Appendix Table 2B).

Late Survival Longer Than 90 Days (Groups I and II Combined, $n=463$ ) Donor age and long graft ischemia time were slight but significant risks. Hazard ratios for these were 1.30 (95\% CI 1.02-1.65) and 1.28 (95\% CI 1.05-1.55). Global test of proportional hazards in this selection model had a $P$ value of .84. Hazard ratio for alternate listing was 0.85 (95\% CI $0.35-2.03)$. $P$ value for the selection model was .003 (Appendix Table 2C).

Graft Coronary Artery Disease (Groups I and II Combined, $n=463$ ) The only significant predictor of graft CAD was donor age both by linear (hazard ratio 1.58, 95\% CI 1.23-2.04) and quadratic analyses (hazard ratio 1.43, 95\% CI 1.15-1.77). $P$ value for the global test of proportional hazards for this late-occurring event was .10. $P$ value for the selection model was $<.001$ (Appendix Table 2D). 


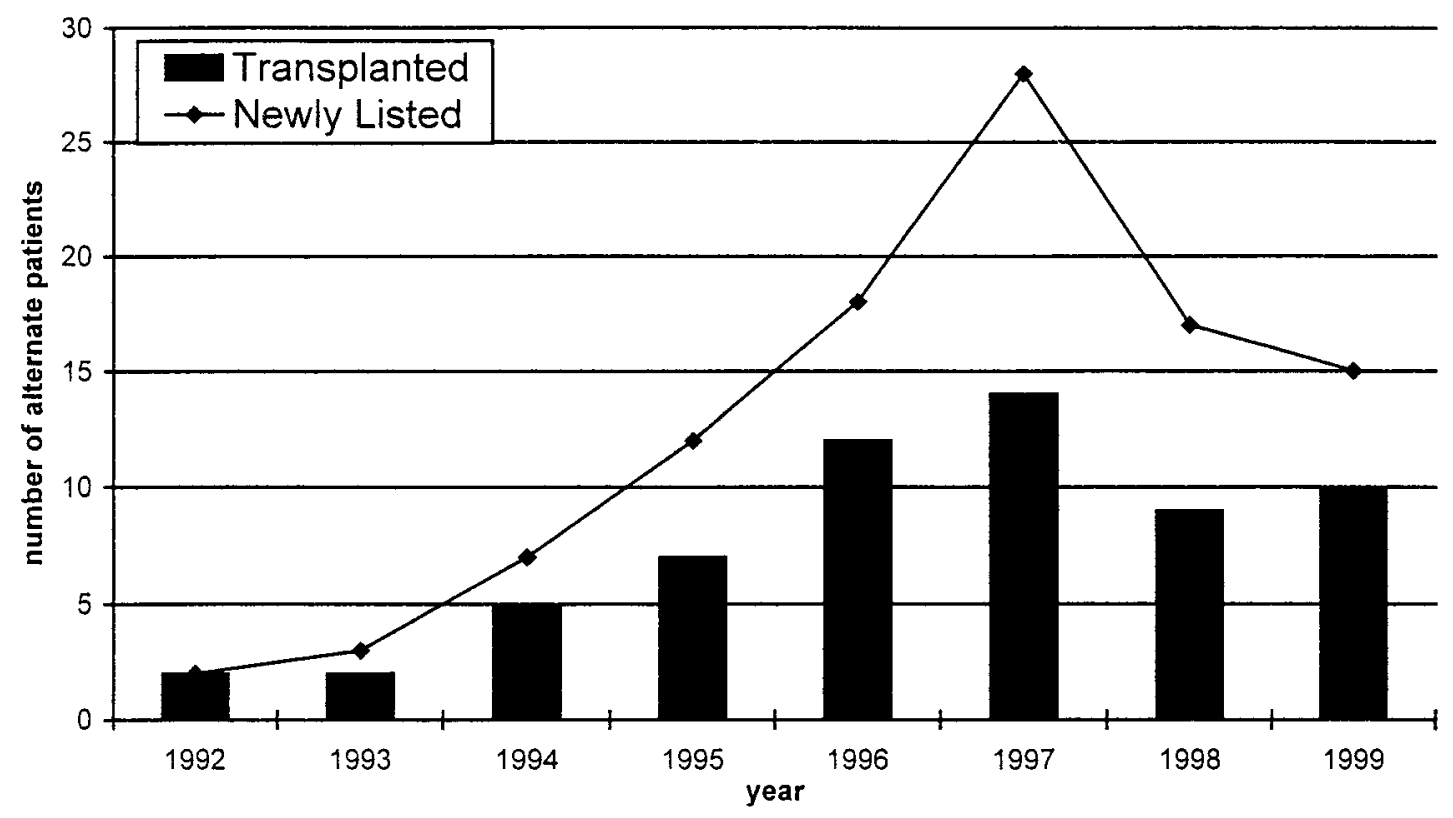

Figure 1. Listed and transplanted alternate recipients.

Early Mortality Among Alternate List Patients (Group I only, $\boldsymbol{n}=62$ ) Only donor cause of death as aICB was predictive of early mortality for alternate recipients (odds ratio 9.68; 95\% CI 1.59-58.9). Goodness-of-fit $\chi^{2} P$ value for this model was .24. None of the recipient risk factors tested were found to be significant (Appendix Table 2E).

\section{Discussion}

Bridging the gap between organ supply and demand in heart transplantation may involve limiting the number of listed recipients to maintain or reduce demand. As the number of older recipients increases disproportionately, another way is to limit a shift in the status quo by ensuring that younger organs are prioritized for younger recipients. ${ }^{2-4}$ Such strategies are currently applied at the two extremes of life; organs from donors younger than 19 years old are prioritized to those of similar age, whereas many programs set age limits for enrollment. These broad guidelines do not address the difference between a 20- and a 70-year-old recipient.

Increasing supply involves extending the margins of what is considered acceptable and has led to the widely used term marginal donor. 5,6 Many extracardiac and cardiac factors may qualify a donor as marginal; this is constantly being updated. The term nonstandard seems appropriate, because the only donor criteria on which the transplant community generally agree are the ideal criteria. These are age of 45 to 55 years, normal cardiac anatomy and function, and negative results of serologic studies. Ischemia times longer than 300 minutes are also generally accepted, but few opportunities exist to go up to the 500-minute mark. ${ }^{12}$
Central to the use of nonstandard donors is allocation, defined as to apportion for a specific purpose or to particular persons. ${ }^{13}$ United Network for Organ Sharing guidelines have acknowledged the fact that not all needs are the same. Some recipients are listed on a more urgent basis than others, and this can change. Given the choice between an assist device and a hepatitis $\mathrm{C}$-seropositive nonstandard donor, one might allocate such a potentially higher risk donor heart to a patient in whom the excess risk is justified (for example, an older patient with previous cardiac surgery). Nonstandard organs would not necessarily be allocated to a much younger recipient who is not in extremis. ${ }^{14}$ This also depends on the circumstances leading to the organs being nonstandard. Thus the concept of matching donor and recipient risk remains fluid and is adjusted for each individual.

What if there are no available recipients for a nonstandard donor? About a third of such donor organs offered to our program cannot be allocated, and therefore a strategy to offer these unused organs to patients who would otherwise not be offered transplantation (mostly because of age) was developed. The current single list system for adult recipients does not formalize this concept. We informed these patients about the risks involved in using such donor organs and explained that they are usually turned down or used only for certain status I patients. We observed that we could decrease the number of unallocated organs and use them for a specific group of the potential recipient pool. Median age for alternate recipients was 67 years, compared with 54 years for regular list patients. The comparison group comprised 


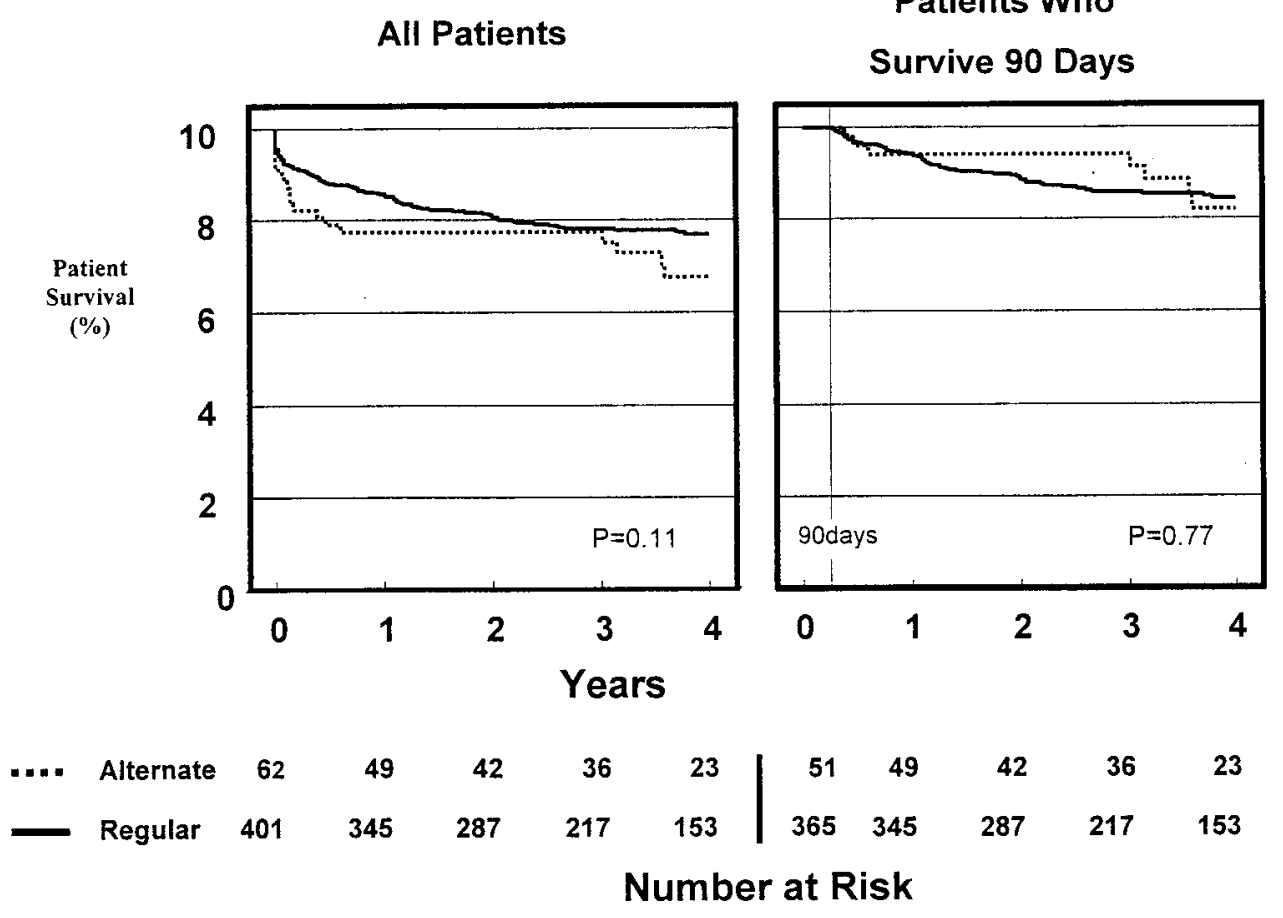

Figure 2. Actuarial survivals of alternate and regular list heart transplant recipients.

all patients that could have potentially used the donor hearts allocated to the alternates by virtue of size.

We found that between 1992 and 1999 a third of nonstandard organs accepted by our program went to alternates. This demonstrates that most are being used selectively in regularly listed recipients in whom the added risk is justified. ${ }^{8,15,16}$ Older donors allocated for the alternate list in this study were always associated with another risk, including no coronary angiogram available, CAD, or long distance. Among the 62 alternates, 6 received hearts from donors older than 45 years old. In this study older donor age slightly influenced late mortality, as did longer ischemia. The quadratic effect of donor age on graft CAD may be explained by a previous observation that early mortality is increased for the donor age range of 35 to 55 years, reflecting a more cautious selection bias when using older donors. ${ }^{17}$

Our preservation method was adapted to retrieve higher risk hearts from outside our local area. Alternate recipients had longer mean graft ischemia times. We also observed that the hearts used for alternates came from donors who more often had died of aICB. This was a risk factor on multivariable analysis of groups I and II combined and an even stronger risk when only the alternates were analyzed. This has been noted to be a sensitive but not specific marker for both short- and long-term mortalities and is probably a surrogate for undetected left ventricular hypertrophy. ${ }^{18}$
Alternates who underwent transplantation were older than regular list recipients and more frequently had ischemic cardiomyopathy. These findings suggest less end-organ reserve and higher risk. The significantly increased 90-day mortality for alternates was explained by the observation that the risk factors for early mortality in this study were previous cardiac surgery, poor renal function, and donor death from aICB. This increased risk (18\% vs 9\%) supports keeping these patients on a separate list with consent in advance. Alternates were able to benefit from the shorter waiting times relative to status II patients on the regular list (median 107 vs 158 days).

On the basis of our early results, the age for alternate listing was raised from 65 to 70 years in 1998, according to the reasoning that heart transplants in those older than 65 years was feasible and should not be withheld. The number of alternates newly listed and undergoing transplantation decreased, perhaps reflecting the fact that the current number of patients older than 70 years who require heart transplantation and are acceptable surgical candidates is low. Shorter waiting times were also noted. This led to our current policy of offering both alternate and regular listing for patients older than 65 years. Alternate listing only is offered to those older than 70 years.

Three of the early deaths were associated with donor $\mathrm{CAD}, \mathrm{LVH}$, and long distance from the center; we no longer consider organs with such a triple combination of risk 
factors. Individually, donor hearts with these risk factors are allocated to status I or alternate recipients (CAD) and to smaller size status I or alternates $(\mathrm{LVH})$. Long distance aggravates LVH. ${ }^{8}$ Other deaths were from multisystem organ failure related to recipient risk factors in combination with generally higher risk donors. Three had renal insufficiency as well as representing retransplantation. One patient who died of volvulus illustrates the pathologic features specific to aging. Multivariable analysis of the factors affecting early mortality specifically in alternates alone did not show any recipient trends. After 90 days the death rates for both groups were comparable. On the basis of preoperative maximal oxygen consumption, this current survival is better than that which would be expected if these patients did not undergo transplantation. ${ }^{19}$ A separate report on quality of life among these generally older recipients is needed to better define this benefit.

Freedom from rejection for alternates within the first year was $90 \%$, versus $70 \%$ for those on the regular list. This lower rejection rate was probably due to immunosenescence in older patients, which permits a reduced immunosuppression in these patients. All recipients in our institution are started on cholesterol-lowering therapy. ${ }^{20,21}$ Alternate recipients did not have increased graft CAD, after those receiving hearts with preexisting disease were excluded. To date, the longest survival of a revascularized donor heart is more than 7 years. Donor CAD appeared to be a risk factor for early graft failure when combined with other factors that aggravated ischemic insult but not independently when selectively used.

Alternate recipients currently account for about $10 \%$ of our program's yearly transplants. This model may provide a partial solution for the current increased waiting times for heart transplantation and the growing number of older recipients. Such a strategy might be complemented by destination therapy with mechanical devices should these alternately listed patients require continuous inotropic support.

\section{Members of the Heart Transplant Program, University of California, Los Angeles}

Rocky Camara, RN, Fardad Esmailian, MD, Antoine Hage, MD, Nobuyuki Kawata, MD, Bernard Kubak, MD, Mark Plunkett, MD, Ali Sadeghi, MD, PhD, Saleh Salehmoghaddam, MD.

\section{References}

1. Stevenson LW. When is heart failure a surgical disease? In: Rose EA, Stevenson LW, editors. Management of end-stage heart disease. New York: Lippincott-Raven; 1998. p. 129-46.

2. Annual report of the US Scientific Registry of Transplant Recipients and the Organ Procurement and Transplantation Network: transplant data 1989-1998 [monograph online] 2000 Feb 21 [cited 2001 Jul 8]. Available from: URL:http://www.unos.org/Data/anrpt_main.htm

3. Renlund DG, Taylor DO, Kfoury AG, Shaddy RS. New UNOS rules: historical background and implications for transplantation management. J Heart Lung Transplant. 1999;18:1065-70.

4. Borkon AM, Muehlebach GF, Jones PG, Bresnahan DR, Genton RE, Gorton ME, et al. An analysis of the effect of age on survival after heart transplant. J Heart Lung Transplant. 1999;18:668-74.

5. Sweeney MS, Lammermeier DE, Frazier OH, Burnett CM, Haupt HM, Duncan JM. Extension of donor criteria in cardiac transplantation: surgical risk versus supply-side economics. Ann Thorac Surg. 1990;50:7-10

6. Young JB, Naftel DC, Bourge RC, Kirklin JK, Clemson BS, Porter $\mathrm{CB}$, et al. Matching the heart donor and heart transplant recipient: clues for successful expansion of the donor pool: a multivariable, multiinstitutional report. The Cardiac Transplant Research Database Group. J Heart Lung Transplant. 1994;13:353-65.

7. Mudge GH, Goldstein S, Addonizio LJ, Caplan A, Mancini D, Levine TB, et al. 24th Bethesda conference: Cardiac transplantation. Task Force 3: recipient guidelines/prioritization. J Am Coll Cardiol. 1993; 22:21-31.

8. Laks H, Marelli D, Fazio D, Kobashigawa JA. Expanding the heart donor base. Curr Opin Organ Transplant. 2000;5:134-8.

9. Stein DG, Drinkwater DC, Laks H, Permut LC, Sangwan S, Chait HI, et al. Cardiac preservation in patients undergoing transplantation: a clinical trial comparing University of Wisconsin solution and Stanford solution. J Thorac Cardiovasc Surg. 1991;102:657-65.

10. Leyh RG, Jahnke AW, Kraatz EG, Sievers HH. Cardiovascular dynamics and dimensions after bicaval and standard cardiac transplantation. Ann Thorac Surg. 1995;59:1495-500.

11. Billingham ME, Cary NR, Hammond ME, Kemnitz J, Marboe C, McCallister HA, et al. A working formulation for the standardization of nomenclature in the diagnosis of heart and lung rejection: Heart Rejection Study Group. The International Society for Heart Transplantation. J Heart Lung Transplant. 1990;9:587-93.

12. Pflugfelder PW, Thomson D, Singh NR, Menkis AH, McKenzie FN, Kostuk WJ. Cardiac allograft ischemic time: relation to graft survival and cardiac function. Circulation. 1989;80(5 Pt 2):III116-21.

13. Webster's Ninth New Collegiate Dictionary. Springfield (MA): Merriam-Webster; 1990. p. 72

14. Ong JP, Barnes DS, Younossi ZM, Gramlich T, Yen-Lieberman B, Goormastic $\mathrm{M}$, et al. Outcome of de novo hepatitis $\mathrm{C}$ virus infection in heart transplant recipients. Hepatology. 1999;30:1293-48.

15. Jeevanandam V, Furukawa S, Prendergast TW, Todd B, Isen HJ, McClurken JB. Standard criteria for an acceptable donor heart are restricting heart transplantation. Ann Thorac Surg. 1996;62:1268-75.

16. Young JB. Age before beauty: the use of "older" donor hearts for cardiac transplantation. J Heart Lung Transplant. 1999;18:488-91.

17. Marelli D, Laks H, Fazio D, Sadeghi A, Ardehali A, Moriguchi J, et al. The use of marginal donor hearts (abstract). J Heart Lung Transplant. 2000;19:76.

18. Tsai FC, Marelli D, Bresson J, Gjerston D, Kerman R, Patel J, et al. Use of hearts transplanted from donors with atraumatic intracranial bleeds. J Heart Lung Transplant. 2002;21:623-8.

19. Mancini DM, Eisen H, Kussmaul W, Mull R, Edmunds LH, Wilson JR. Value of peak exercise oxygen consumption for optimal timing of cardiac transplantation in ambulatory patients with heart failure. Circulation. 1991;83:778-86.

20. Costanzo MR, Naftel DC, Pritzker MR, Heilman JK, Boehmer JP, Brozena SC, et al. Heart transplant coronary artery disease detected by coronary angiography: a multiinstitutional study of preoperative donor and recipient risk factors. Cardiac Transplant Research Database. J Heart Lung Transplant. 1998;17:744-53.

21. Kobashigawa JA, Katznelson S, Laks H, Johnson JA, Yeatman L, Wang XM, et al. Effect of pravastatin on outcomes after cardiac transplantation. $N$ Engl J Med. 1995;333:621-7. 


\section{Appendix TABLE 1. Nonstandard donor criteria}

\begin{tabular}{|c|c|c|}
\hline Risk factor & $\begin{array}{l}\text { Nonstandard } \\
\text { donors* }(\%)\end{array}$ & Definition \\
\hline \multicolumn{3}{|l|}{ Cardiac } \\
\hline CAD & 5 & $\begin{array}{l}\text { Any coronary artery stenosis evident on coronary } \\
\text { angiogram or greater than mild calcified plaque }\end{array}$ \\
\hline Age $>45$ y, coronary angiogram not available & 2 & Normal function on echocardiogram \\
\hline LVH by electrocardiographic criteria & 2 & Abnormal $R$ wave on electrocardiogram in $V_{5}$ and $V_{6}$ \\
\hline LVH by echocardiogram & 15 & Posterior wall thickness $\geq 14 \mathrm{~mm}$ (at least moderate) \\
\hline Low left ventricular ejection fraction & 9 & $<50 \%$ on echocardiogram \\
\hline High-dose inotropic requirement & 1 & $\begin{array}{l}1 \text { inotrope at maximal dose or } 2 \text { inotropes at greater } \\
\text { than half maximal dose (dopamine and dobutamine } \\
\text { maximal dose } 20 \mu \mathrm{g} /[\mathrm{kg} \cdot \mathrm{min}] \text { ) }\end{array}$ \\
\hline Suspected myocardial contusion secondary to chest trauma & 21 & $\begin{array}{l}\text { Significant anterior blunt chest injury with right } \\
\text { ventricular or septal wall motion abnormality on } \\
\text { echocardiogram }\end{array}$ \\
\hline Recent cardiac arrest requiring advanced cardiac life support & 15 & Organ retrieved less than $24 \mathrm{~h}$ after cardiac arrest \\
\hline Reused donor heart & 1 & $\begin{array}{l}\text { Perioperative cerebrovascular accident in heart } \\
\text { transplantation leading to brain death and organ } \\
\text { donation }\end{array}$ \\
\hline \multicolumn{3}{|r|}{ 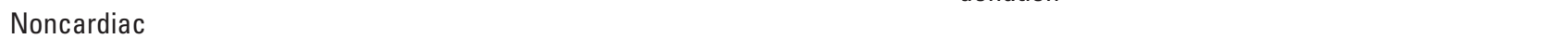 } \\
\hline Older age & 17 & Age $>55$ y \\
\hline Hepatitis B seropositivity & 1 & $\begin{array}{l}\text { Immunoglobulin G core antibody positive; } \\
\text { immunoglobulin } \mathrm{M} \text { unknown }\end{array}$ \\
\hline Hepatitis C seropositivity & 11 & Positive antibody titer \\
\hline
\end{tabular}

*Figures represent percentages of all nonstandard donors (1992-1999, $n=182) ; 62$ of these were allocated to alternates.

\section{Appendix TABLE 2A. Covariates used in the multivariable analysis}

\begin{tabular}{ll}
\hline Covariate & \\
\hline Recipients & Notes \\
$\begin{array}{l}\text { Alternate list patient } \\
\text { Recipient male }\end{array}$ & As defined in this study \\
Recipient age (standard units $=52 \pm 15 \mathrm{y})$ & In years \\
Previous cardiac surgery & Any \\
Retransplantation & Retransplantation because of chronic graft CAD \\
Renal function (standard units $=1.5 \pm 0.8 \mathrm{mg} / \mathrm{dL})$ & Serum creatinine \\
Donors & \\
Donor male & \\
Donor age (standard units $=33 \pm 14 \mathrm{y})$ & In years \\
Donor death from alCB & Atraumatic \\
Graft ischemia time (standard units $=193 \pm 67)$ & In minutes \\
Donor history of CAD & See Appendix Table 1 \\
Donor LVH & Electrocardiographic or echocardiographic criteria (Appendix Table 1)
\end{tabular}


Appendix TABLE 2B. Early mortality $(n=463)$

\begin{tabular}{|c|c|c|c|c|}
\hline \multirow[b]{2}{*}{ Logistic regression covariate } & \multicolumn{2}{|c|}{ Full model $(P<.001)$} & \multicolumn{2}{|c|}{ Selection model $(P<.001)$} \\
\hline & Odds ratio & $95 \% \mathrm{Cl}$ & Odds ratio & $95 \% \mathrm{Cl}$ \\
\hline Alternate list patients & 1.36 & $0.53-3.50$ & & \\
\hline Recipient male & 0.67 & $0.30-1.48$ & & \\
\hline Recipient age & 0.98 & $0.67-1.43$ & & \\
\hline Previous cardiac surgery & 2.70 & $1.28-5.68$ & 2.74 & $1.37-5.48$ \\
\hline Retransplantation & 1.63 & $0.53-5.00$ & & \\
\hline $\begin{array}{l}\text { Renal function (serum creatinine, standard } \\
\text { units }=1.5 \pm 0.8 \mathrm{mg} / \mathrm{dL} \text { ) }\end{array}$ & 1.39 & $1.08-1.79$ & 1.39 & $1.10-1.76$ \\
\hline Donor male & 0.85 & $0.40-1.78$ & & \\
\hline Donor age (standard units $=33 \pm 14$ y) & 1.06 & $0.71-1.59$ & & \\
\hline Donor death from aICB & 2.42 & $1.08-5.40$ & 2.84 & $1.51-5.34$ \\
\hline Graft ischemia time (standard units $=193 \pm 67 \mathrm{~min}$ ) & 1.20 & $0.90-1.59$ & & \\
\hline Donor history of CAD & 0.88 & $0.15-5.13$ & & \\
\hline Donor LVH & 1.52 & $0.58-3.95$ & & \\
\hline Goodness-of-fit $\chi^{2} P$ value & .49 & & .54 & \\
\hline
\end{tabular}

Appendix TABLE 2C. Late mortality $(n=463)$

\begin{tabular}{|c|c|c|c|c|}
\hline \multirow[b]{2}{*}{ Cox regression covariate } & \multicolumn{2}{|c|}{ Full model $(P=.04)$} & \multicolumn{2}{|c|}{ Selection model $(P=.003)$} \\
\hline & Hazard ratio & $95 \% \mathrm{Cl}$ & Hazard ratio & $95 \% \mathrm{Cl}$ \\
\hline Alternate list patients & 0.85 & $0.35-2.03$ & & \\
\hline Recipient male & 1.33 & $0.70-2.53$ & & \\
\hline Recipient age (standard units $=52 \pm 15$ y) & 0.82 & $0.63-1.07$ & & \\
\hline Previous cardiac surgery & 1.19 & $0.70-2.01$ & & \\
\hline Retransplantation & 1.74 & $0.66-4.59$ & & \\
\hline Renal function (serum creatinine, standard units $=1.5 \pm 0.8 \mathrm{mg} / \mathrm{dL}$ ) & 1.14 & $0.91-1.43$ & & \\
\hline Donor male & 0.80 & $0.45-1.43$ & & \\
\hline Donor age (standard units $=33 \pm 14$ y) & 1.43 & $1.05-1.95$ & 1.30 & $1.02-1.66$ \\
\hline Donor death from aICB & 0.81 & $0.44-1.50$ & & \\
\hline Graft ischemia time (standard units $=193 \pm 67 \mathrm{~min}$ ) & 1.32 & $1.07-1.64$ & 1.28 & $1.05-1.55$ \\
\hline Donor history of CAD & 1.11 & $0.27-4.50$ & & \\
\hline Donor LVH & 0.56 & $0.21-1.52$ & & \\
\hline Global test of proportional hazards $P$ value & .56 & & .84 & \\
\hline
\end{tabular}


Appendix TABLE 2D. Graft CAD-free graft survival $(n=463)$

\begin{tabular}{|c|c|c|c|c|}
\hline \multirow[b]{2}{*}{ Cox regression covariate } & \multicolumn{2}{|c|}{ Full model $(P<.001)$} & \multicolumn{2}{|c|}{ Selection model $(P<.001)$} \\
\hline & Hazard ratio & $95 \% \mathrm{Cl}$ & Hazard ratio & $95 \% \mathrm{Cl}$ \\
\hline Alternate list patients & 1.45 & $0.65-3.26$ & & \\
\hline Recipient male & 0.89 & $0.50-1.59$ & & \\
\hline Recipient age (standard units $=52 \pm 15$ y) & 0.86 & $0.57-1.30$ & & \\
\hline Previous cardiac surgery & 0.98 & $0.58-1.66$ & & \\
\hline Retransplantation & 2.15 & $0.75-6.17$ & & \\
\hline Renal function (serum creatinine, standard units $=1.5 \pm 0.8 \mathrm{mg} / \mathrm{dL}$ ) & 1.01 & $0.78-1.32$ & & \\
\hline Donor male & 1.56 & $0.87-2.79$ & & \\
\hline \multicolumn{5}{|l|}{ Donor age (standard units $=33 \pm 14$ y) } \\
\hline Linear & 1.45 & $1.08-1.96$ & 1.58 & $1.23-2.04$ \\
\hline Quadratic & 1.40 & $1.82-1.26$ & 1.43 & $1.15-1.77$ \\
\hline Donor death from aICB & 1.26 & $0.71-2.24$ & & \\
\hline Graft ischemia time (standard units $=193 \pm 67$ ) & 0.98 & $0.76-1.27$ & & \\
\hline Donor history of CAD & 1.26 & $0.40-3.99$ & & \\
\hline Donor LVH & 1.10 & $0.53-2.28$ & & \\
\hline Global test proportional hazards $P$ value & .43 & & .1 & \\
\hline
\end{tabular}

Appendix TABLE 2E. Early mortality among alternate list recipients $(n=62)$

\begin{tabular}{|c|c|c|c|c|}
\hline \multirow[b]{2}{*}{ Logistic regression covariate } & \multicolumn{2}{|c|}{ Full model $(P=.09)$} & \multicolumn{2}{|c|}{ Selection model $(P=.002)$} \\
\hline & Odds ratio & $95 \% \mathrm{Cl}$ & Odds ratio & $95 \% \mathrm{Cl}$ \\
\hline Recipient age (standard units $=52 \pm 15$ y) & 0.37 & $0.04-3.58$ & & \\
\hline Previous cardiac surgery & 1.54 & $0.22-11.0$ & & \\
\hline Retransplantation & 0.21 & $0.00-11.0$ & & \\
\hline Renal function (serum creatinine, standard units $=1.5 \pm 0.8 \mathrm{mg} / \mathrm{dL}$ ) & 1.27 & $0.40-4.00$ & & \\
\hline Donor male & 3.88 & $0.52-29.0$ & & \\
\hline Donor age (standard units $=33 \pm 14 \mathrm{y}$ ) & 0.82 & $0.28-2.36$ & & \\
\hline Donor death from aICB & 8.22 & $0.93-72.8$ & 9.68 & $1.59-58.9$ \\
\hline Graft ischemia time (standard units $=193 \pm 67$ ) & 1.76 & $0.85-3.63$ & & \\
\hline Donor history of CAD & 1.47 & $0.16-13.6$ & & \\
\hline Donor LVH & 1.46 & $0.22-9.67$ & & \\
\hline Goodness-of-fit $\chi^{2} P$ value & .23 & & .24 & \\
\hline
\end{tabular}


Appendix TABLE 3. Patient deaths

\begin{tabular}{|c|c|c|c|}
\hline Cause of death & $\begin{array}{c}\text { Alternates } \\
(\mathrm{n}=62)\end{array}$ & $\begin{array}{c}\text { Regular } \\
(\mathrm{n}=401)\end{array}$ & $P$ value \\
\hline All deaths & 21 & 93 & \\
\hline$<90 \mathrm{~d}$ after operation & & & .97 \\
\hline Graft failure & 3 & 7 & \\
\hline Infection & 2 & 6 & \\
\hline Rejection & 1 & 5 & \\
\hline Multisystem organ failure & 3 & 12 & \\
\hline Cerebrovascular accident & 2 & 4 & \\
\hline Other & 0 & 2 & \\
\hline Total & 11 & 36 & \\
\hline 90-d actuarial survival & $82 \%$ & $91 \%$ & \\
\hline $90 \mathrm{~d}-1$ y after operation & & & .88 \\
\hline Infection & 0 & 2 & \\
\hline Rejection & 1 & 6 & \\
\hline Graft CAD & 0 & 4 & \\
\hline Multisystem organ failure & $1^{*}$ & 4 & \\
\hline Cerebrovascular accident & 0 & 2 & \\
\hline Other & 0 & 1 & \\
\hline Not stated & 0 & 2 & \\
\hline Total & 3 & 21 & \\
\hline 1-y actuarial survival & $77 \%$ & $86 \%$ & \\
\hline$>1$ y after operation & & & .36 \\
\hline Graft failure & 0 & 1 & \\
\hline Infection & 0 & 4 & \\
\hline Rejection & 0 & 4 & \\
\hline Graft CAD & 2 & 7 & \\
\hline Multisystem organ failure & 2 & 3 & \\
\hline Cerebrovascular accident & 0 & 1 & \\
\hline Cancer & 1 & 1 & \\
\hline Pulmonary embolism & 1 & 1 & \\
\hline Other & 0 & 7 & \\
\hline Not stated & 1 & 7 & \\
\hline Total & 7 & 36 & \\
\hline
\end{tabular}

$P$ values testing the equality of distributions of deaths between the two groups were calculated by Fisher exact test for categoric variables. * Sigmoid volvulus.

\section{Bound volumes available to subscribers}

Bound volumes of The Journal of Thoracic and Cardiovascular Surgery are available to subscribers (only) for the 2003 issues from the Publisher, at a cost of $\$ 134.00$ for domestic, $\$ 165.85$ for Canadian, and $\$ 155.00$ for international subscribers for Vol 125 (January-June) and Vol 126 (July-December). Shipping charges are included. Each bound volume contains a subject and author index and all advertising is removed. The binding is durable buckram with the Journal name, volume number, and year stamped in gold on the spine. Payment must accompany all orders. Contact Mosby, Subscription Customer Service, 6277 Sea Harbor Dr, Orlando, FL 32887, USA; phone 800-654-2452 or 407-345-4000.

Subscriptions must be in force to qualify. Bound volumes are not available in place of a regular Journal subscription. 